\title{
Cognitive and Metacognitive Skills Performed by Math Teachers in the Proving Process of Number Theory
}

\author{
By Mesut Ozturk*
}

\begin{abstract}
Evaluating the proving process of mathematics teachers is important for the development of their proof skills. Developing the proof skills of teachers can contribute to their students' meaningful learning of mathematics. For example, teachers showing simple proofs about number theory can make it easier for students to understand the concepts of multipliers and factors and the concepts of the greatest common divisor and the least common multiple. Within this context, this study was conducted in order to examine the cognitive and metacognitive skills performed by math teachers in the proving process. The study was conducted as a case study using qualitative research design. A total of 14 teachers participated in the study, six of which were elementary math teachers and eight were secondary math teachers. The data were collected through task-based interviews (think-aloud protocol), documents and observation forms. The collected data were analysed using the content analysis method. The results of the study showed that, based on the operational definition of cognition and metacognitive skills made in this study, elementary math teachers generally used cognitive skills, while secondary mathematics teachers performed metacognitive skills.
\end{abstract}

Keywords: proof, math teachers, number theory, elementary, secondary

\section{Introduction}

Studies in the literature emphasize that proof is important for mathematics education as proof requires a high level of mathematical thinking and systematic work. However, many students and teachers think that proof is difficult to both write and understand (Öztürk\& Kaplan, 2019). Thus, they do not tend to lean towards the proof process (Knuth, 2002; Raman, 2003). The knowledge and thoughts students have regarding proof are related to the knowledge and thoughts their teachers have on the subject. Therefore, it is important to examine the knowledge and thoughts math teachers have regarding proof. Math teachers with advanced proof skills are able to work systematically and perform high level mathematical thinking skills. The math learning process of the students of such teachers can be positively affected as mathematical proof requires advanced cognitive skills and awareness. The awareness of cognition is generally defined as a metacognitive skill (Öztürk \& Kaplan, 2019). Mathematical proof is extremely important for math teachers, however the math curriculum applied in schools in Turkey does not contain enough proof related subjects. The Trends in International Mathematics and Science Study (TIMSS) and the Programme for International Student Assessment (PISA) have both reported that Turkish students have low mathematics skills. The negative results obtained from the TIMSS and PISA led to the conducting of this study, which aimed to compare the cognitive and

${ }^{*}$ Assistant Professor, Bayburt University, Turkey. 
metacognitive skills performed by elementary and secondary math teachers in the proving process.

\section{Proof in Mathematics Education and Mathematical Proof}

Mathematical proof is the process of determining whether a claim is correct or not by using mathematical symbols and formulas. The aim of proof in mathematics education is to convince the students of the accuracy or inaccuracy of mathematical propositions (Aydoğdu-İskenderoğlu, 2016, p. 66). These definitions show that there are small but significant differences in the concept of proof in math and math education. The main point of distinction is that there is a multiple type of proof in mathematics education while there is only one type in mathematics. Therefore, the purpose of the proof is different in both disciplines. In mathematics, the first demonstration of a theorem's accuracy is proof, and all subsequent representations of accuracy (demonstration of accuracy in different ways) are representations. The proof contributes to the systematic development of math. Once a theorem has been proven, the proof of the other theorems that will use the proven theorem as a lemma begins. Unlike math, in math education, proof is used for understanding theorems, but also for developing mathematical thinking and understanding mathematical concepts (Dawkins \& Weber, 2017).

Many mathematics educators consider proof as an important part of math courses and point out that it is necessary to know how to make proofs for mathematical applications (Öztürk, Akkan \& Kaplan, 2019).Hanna and de Villiers (2008) stated that in order to gain the necessary skills to make proofs, individuals should be introduced to proofs from early ages. They also determined that math curriculums and the attitudes and knowledge of teachers are important to make proofs. In general, the number theory course is a course that includes the most proofs in the math curriculum. This course and the proofs are related to the maths subjects in K-12 education. Therefore, it is important to consider the proofs in the number theory course. In addition, number theory is one of the basic courses of maths education. Number theory forms the basis for other courses such as algebra. If math teachers gain a high level of skills to make proofs, they can teach math conceptually and by justifying the accuracy of a claim. The acceptance of a claim is related to the validity of the proof. For a proof to be valid, it must be both reliable and true for each claim or premise (Tall \& Mejia-Ramos, 2010). All this is possible through systematic studying and the development of metacognitive skills.

\section{Cognition and Metacognition}

Cognition is the structure that involves all of the operations in the process of completing a task (Öztürk \& Kaplan, 2019). It is a mental condition that can be used by individuals (Husamah, 2015) and does not require an advance level of skill. In other words, it refers to the processes and strategies used by an individual to complete a task (Öztürk \& Kaplan, 2019). Forrest-Pressley and Waller (1984) 
considered cognition as a recollection of an individual's knowledge. Metacognition, on the other hand, is when an individual is aware of his/her tactic and strategy knowledge or can monitor his/her cognition (Winne \& Azevedo, 2014).

Metacognition means being aware of one's knowledge and being able to organize this knowledge (Flavell, 1976). In other words, metacognition is when an individual is aware of his/her own thinking procedures and is able to change and organize his/her own thinking (Spruce \& Bol, 2015). There are two basic categorizations of the concept of metacognition: (1) the knowledge of cognition, where the individual is aware of how he/she learns and (2) the regulation of cognition which is being able to plan, control, monitor and evaluate one's knowledge (Garner \& Alexander, 1989).

The distinction between cognition and metacognition is related to how knowledge is used and what the object of the process is. The skills required to complete a task such as knowing strategies, using representations are cognitive skills, while the awareness of these skills and thinking in regards to these skills are metacognitive skills (Öztürk \& Kaplan, 2019; Winne \& Azevedo, 2014). Weinert (1987) explained metacognition as the awareness of cognition and defined it as being the second degree of cognition, in other words, as thinking about thinking. Winne and Azevedo (2014) described metacognition as the cognitive features of information in the learning process. Note-taking, recognising operational errors and comparing results when evaluating a subject or performing a task were evaluated as metacognitive skills. When performing the same task, copying and using a ready-to-use formula that has been memorized instead of taking notes are evaluated as cognitive skills. These skills provide a distinction between cognitive and metacognitive knowledge (Öztürk \& Kaplan, 2019). The distinction between metacognitive skills and cognitive skills is that the former requires awareness, high-level thinking or critical thinking, while the latter are used to perform a task without the use of any similar skills (automated skills) (Akın, 2013, p. 123).

\section{The Purpose of the Study}

The literature in mathematics education shows that there has been an increase in the studies conducted on mathematical proof in recent years. This demonstrates the importance of proof. When the developmental stages of the studies conducted on mathematics education were examined, it was seen that firstly descriptive studies had been conducted, then these were followed by studies examining opinions and finally studies investigating cognitive structures had been carried out. The literature regarding proof in math education showed that descriptive studies and studies on opinion analysis were adequate; however, studies on cognitive structure were inadequate. Öztürk and Kaplan (2019) collected the cognitive structures of secondary math teachers in the proving process in two themes: cognitive and metacognitive. However, their study was limited to secondary math teachers and did not reveal the conditions among elementary math teachers. Uncovering the proving process of primary and secondary mathematics teachers in Turkey, while emphasizing the current status of mathematics teachers will make it 
possible to compare the primary and secondary school mathematics teachers. In this context the present study aimed to determine the cognitive and metacognitive skills performed by math teachers in the proving process. In accordance with this purpose, the answers to the following research questions were sought in the present study:

1. What are the cognitive and metacognitive skills performed by elementary math teachers in the proving process?

2. What are the cognitive and metacognitive skills performed by secondary math teachers in the proving process?

3. What are the differences between the cognitive and metacognitive skills of elementary and secondary math teachers?

\section{Method}

\section{Research Model}

The study was conducted as a case study using qualitative research design. Case studies aim to provide an in-depth examination and explanation of a phenomenon or a case using a variety of data sources (Creswell, 2007). There are various types of case studies including explanatory, descriptive and multiple-case studies (Baxter \& Jack, 2008). For the present study multiple-case study was selected. Multiple-case studies are used to explore the differences within and between cases (Baxter \& Jack, 2008). Multiple-case study was selected for the present study in order to compare the cognitive and metacognitive skills used by elementary and secondary math teachers in the proving process.

\section{Participants}

The study was conducted with 14 in-service math teachers. Firstly, a total of 50 teachers, 28 of which were elementary and 22 were secondary math teachers, were interviewed for the selection of the sample. The teachers where asked general questions such as "Do you think that you are qualified in proving?" and "Can you perform a proof without assistance from others?". Through this unstructured interview, those of the teachers who considered themselves inadequate by expressing that they could only perform memorized proofs or those who stated that their thinking levels were not adequate for making proofs were removed from the study. Consequently, a total of 14 math teachers, six of which were elementary math teachers and eight of which were secondary math teachers participated in the study voluntarily. Fifty percent of elementary and secondary math teachers were female and the other fifty percent of them were male. Two of the elementary math teachers and three of the secondary math teachers had 1-5 years of experience, three of the elementary and secondary math teachers had 6-10 years of experience, one of the elementary and secondary math teachers had 11-15 years of experience and one of the secondary math teachers had 16-20 years of experience. In this 
study, all participants were informed regarding the study and ensured that their personal information would not be shared with anybody. The ethnicity of the participants was Turkish. Code names were used for the participants during direct transfers. The code names were created by using the $T_{i j}$ matrix encoding. According to this coding, Teacher $=\mathrm{T}$; i: Elementary math teacher $=\mathrm{E}$, Secondary math teachers $=\mathrm{S}$; $\mathrm{j}$ : teacher number $=1-8$. For example, $\mathrm{T}_{\mathrm{E} 1}$ : Number one elementary math teacher. The R symbol represents the Researcher's code.

\section{Instrument}

Metacognitive skills can generally be examined through the verbal reactions given by the person to a situation encountered in the proving process. For example, when faced with an obstacle during a problem-solving process, the difficulty in solving the problem alone and needing help may reveal metacognitive skills with the help of verbal expressions (Veenman, Hout-Wolters \& Afflerbach, 2006). However, determining metacognitive skills through verbal expressions may not be sufficient in every case. For example, the metacognitive planning skill of determining the suitable strategy in the problem-solving process and making systematic operations accordingly requires the examination of not only verbal expressions, but also written expressions (Veenman et al., 2006). In this context, in order to demonstrate the operations in the proving process and determine the metacognitive skills from verbal expressions, task-based interviews were used in the study. Observation forms were utilized to determine the non-verbal section of the skills performed in more detail. Garner and Alexander (1989) emphasized that due to the difficulty in determining metacognitive skills using multiple data collection tools is more beneficial.

In the first stage of the observation forms, four written questions on proving were prepared to be used in the task-based interviews. The prepared questions were asked to two faculty members in the math education field and to two in the mathematics field and their opinions were noted. In line with their opinions, two questions for the task-based interviews were prepared based on symbolic and verbal expressions. The chosen questions were implemented to one elementary and one secondary math teacher. As a result of the implementation, it was determined that the problems were solvable for teachers and that they could be sufficient in terms of demonstrating the process. In the task-based interviews, the teachers were asked to make the proof by using the thinking aloud protocol method. By doing so it was aimed to reveal the immediate thoughts of the teachers and the questions they ask themselves during this process. The task-based interview questions used in the study are presented in Table 1. 
Table 1. The Task Based Interview Questions Used in the Study and the Reasons for their Use

\begin{tabular}{|l|l|}
\hline & Question content \\
\hline & $\begin{array}{l}\text { Based on Verbal Expression } \\
\text { Show that the expression "On the integers set, every number divisible by } 3 \text { and } 4 \text { can } \\
\text { be divided into 12" is correct. } \\
\text { 1. Is this proposition correct? Why? (How they do intuitive reasoning will be } \\
\text { examined). }\end{array}$ \\
2. Is the proof you carried out valid? Why and how did you decide? \\
3. Why did you do the operations you did? (It is asked suitably for every \\
performed operation). \\
4. Show that the expression "On the set of integers, every number divisible by \\
7 and 9 can be divided into 63 " is correct.
\end{tabular}

The reasons for selecting the first question are as follows: this question is at a suitable level for all teachers to solve, its accuracy can be demonstrated through different proving methods, it is suitable in terms of examining whether all the conditions are checked for valid proof, it is easy to express verbally and it allows the examination of whether symbolic expressions are used or not. The reasons for selecting the second question are as follows: it contains symbolic expressions; it is suitable in terms of examining whether symbolic expressions are understood and it is important in terms of determining whether all conditions are checked in the generalization of the proof.

For the observations, a semi-structured observation form developed by the researchers was used. The form was revised and reorganized after the interviews and prepared as a 3-point Likert type, in accordance with the task-based interviews. If the determined skill was not performed in any of the problems, the option " 0 " was ticked, if it was performed in one problem option " 1 " was ticked and if it was performed in two problems option " 2 " was ticked. Moreover, records were made in the explanation section for various skills exhibited by the teachers during the process.

\section{Data Analysis}

The data were analyzed using the content analysis method. According to this method the collected data were first encoded. In other words, sub-categories were constructed. During the initial encodings, only the skills were determined. Later, the encodings and the questions asked were re-examined, and the replies from the teachers and studies in the literature (Cozza \& Oreshkina, 2013; Schoenfeld, 1985; 
Yang, 2012) were utilized to demonstrate whether the skills were cognitive or metacognitive. The data were encoded by the first researcher and determined as suitable or unsuitable by the second researcher. At the end of this process, the consistence between the two researchers was checked with the Cohen Kappa formula. The consistence between the researchers was calculated as .84, which indicated that the value coding was highly reliable (Landis \& Koch, 1977). The sub-categories were categorized according to their common traits. In the study, task-based interviews took, on average, approximately 30 minutes. In cases where the cognitive or metacognitive characteristics of the skill could not be decided from the replies, the teacher was interviewed again. Direct quotations of the teachers' opinions and solutions were added.

\section{Validity and Reliability}

Internal validity and external validity studies were conducted to confirm the validity of the study. The internal validity of the study was increased by using different data collection tools together. The external validity of the study was increased by explaining participation in detail and taking direct excerpts from the statements of the participants.

To ensure the reliability of the study, it was made sure that the research process was consistent within itself (research model, participants, data collection tools and analysis of collected data). The research process was carried out by the first researcher while the second and third researchers controlled the research process continuously.

\section{Results}

The results of the study are presented in three parts: (1) cognitive and metacognitive skills performed in the proof process of elementary math teachers, (2) cognitive and metacognitive skills performed in the proof process of secondary math teachers and (3) comparison of cognitive and metacognitive skills in the proof process of elementary and secondary math teachers.

\section{Cognitive and Metacognitive Skills Performed by Elementary Math Teachers in the Proof Process}

The cognitive and metacognitive skills performed by the elementary math teachers in the proof process were collected in three categories: verification, explanation and generalization.

\section{Cognitive and Metacognitive Skills Performed under the Verification Category by the Elementary Math Teachers}

It was determined that the elementary math teachers participating in the study performed three cognitive and three metacognitive skills relevant to the 
verification category. The cognitive skills were "Read the proposition in one", "Reading the proposition step by step" and "Heuristically checking the proposition". The metacognitive skills were "Reading the proposition repeatedly", "Making a guess" and "Drawing a diagram or a table".

The elementary math teachers read the proposition which include two step by step verbal statements. The observation form showed that five elementary math teachers $\left(\mathrm{T}_{\mathrm{E} 1 \mathrm{E} 3 \mathrm{E} 4 \mathrm{E} 5 \mathrm{E} 6}\right)$ read proposition for the first time. In other words, they read the proposition as a whole. The form showed that $\mathrm{T}_{\mathrm{E} 2}$ read the proposition step by step and checked the accuracy of the proposition intuitively. This sub-category was detected with the observation form and task-based interviews. $\mathrm{T}_{\mathrm{E} 1}$ said that "The proof I made was not valid, because the proof I made was very simple and ordinary. In other words, I did not use any symbols. I only wrote the explanation." From this expression it can be said that $\mathrm{T}_{\mathrm{E} 1}$ did not know whether his proof was valid or not. Thus, the sub-category of "Heuristically checking the proposition" was considered as a cognitive skill.

Two of the elementary math teachers read the proposition repeatedly. The opinions of teachers showed that this sub-category was a metacognitive skill. For example, $\mathrm{T}_{\mathrm{E} 2}$ said that:

"I read it a few times to find out what to do. In the first part of the proposition it says that every integer is divisible by 3 and 4 . Does it say every because there are special cases that are not?"

This statement showed that $\mathrm{T}_{\mathrm{E} 2}$ was aware of why he was reading the proposition repeatedly. Thus, it was determined that this sub-category was a metacognitive skill. $\mathrm{T}_{\mathrm{E} 2}$ also said that he guessed the proof of the proposition and then he checked its accuracy in his mind. This sub-category was metacognitively controlled, thus it was considered as a metacognitive skill. Some of participates $\left(\mathrm{T}_{\mathrm{E} 1 \mathrm{E} 3 \mathrm{E} 4 \mathrm{E} 5 \mathrm{E} 6}\right)$ drew diagrams or table and their explanation showed that they aimed to comprehend the proposition by doing so. Thus, it was determined that the subcategory of "drawing a diagram or a table" was a metacognitive skill.

\section{Cognitive and Metacognitive Skills Performed under the Explanation Category by the Elementary Math Teachers}

It was determined that the elementary math teachers participating in the study performed two cognitive and five metacognitive skills relevant to the explanation category. The cognitive skills were "trial-error strategy" and "Proving the opposite of the proposition". The metacognitive skills were "Determining a key idea", "Proving it in his/her mind before writing the proof", "Making a decision", "Asking questions in the proof process" and "Establishing relationship between the steps".

While many teachers decided whether they could make the proof or not, some teachers $\left(\mathrm{T}_{\mathrm{E} 5 \mathrm{E} 6}\right)$ made this decision without thinking and preferred to see the proof by trying. The teachers tried to make the proof of the proposition, however they then decided that they could not. In this sense, the trial-error strategy for proving 
process was considered as a cognitive skill. $\mathrm{T}_{\mathrm{E} 2}$ proved the opposite of the proposition. However, this proof was not valid and the teacher was not aware of it. Thus, the sub-category of "Proving the opposite of the proposition" was considered as a cognitive skill.

It was observed that $\mathrm{T}_{\mathrm{E} 1}$ determined a key idea for proof. The verbal expression of the teacher showed that he was aware of the importance of determining a key idea. Thus, it was considered that the sub-category of "Determining a key idea" was a metacognitive skill. Four of the elementary math teachers $\left(\mathrm{T}_{\mathrm{E} 1 \mathrm{E} 3 \mathrm{E} 4 \mathrm{E} 5 \mathrm{E} 6}\right)$ proved it in their minds before they wrote down the proof. This indicated that they checked the proof in their minds, thus the sub-category of "Proving it in his/her mind before writing the proof" was determined as a metacognitive skill. $\mathrm{T}_{\mathrm{E} 1}$ stated that he didn't show the proof of the proposition because his knowledge level was not adequate. On the other hand, $\mathrm{T}_{\mathrm{E} 2}$ said that "I think the proof I made is not valid, because I didn't use any symbolic expressions." This expression showed that $\mathrm{T}_{\mathrm{E} 2}$ evaluated the proof himself. Thus, the subcategory of "Making a decision" was considered as a metacognitive skill. Three teachers $\left(\mathrm{T}_{\mathrm{E} 1 \mathrm{E} 2 \mathrm{E} 3}\right)$ asked themselves questions during the proof process. As questioning is a part of metacognition, the sub-category of "Asking questions in the proof process" was considered as a metacognitive skill. In the observation form of $\mathrm{T}_{\mathrm{E} 1}$, it was determined that the participant correlated with the proof steps. Establishing relationships is necessary for metacognitive monitoring. Thus, the sub-category of "Establishing relationship between the steps" was considered as a metacognitive skill.

\section{Cognitive and Metacognitive Skills Performed under the Generalization Category by the Elementary Math Teachers}

It was determined that elementary math teachers performed three cognitive skills and one metacognitive skill relevant to the generalization category. The cognitive skills were "Justifications dependent on authority", "Justifications based on examples" and "Pattern generalization" and the metacognitive skill was "Symbolic justification".

$\mathrm{T}_{\mathrm{E} 2}$ justified the proof of the proposition based on authority and stated the following:

"... when all multiples of 4 are divided by 3 , they give the remainder of 1 . So, if we consider the opposite, i.e. subtracting 1 from the forces of 4 , the number is divided by 3. I've seen this proposition be proven this way before."

These expressions give the impression that $\mathrm{T}_{\mathrm{E} 2}$ based his proof justification to a source he saw before and remained loyal to the authority. It was observed that four of the elementary math teachers $\left(\mathrm{T}_{\mathrm{E} 1 \mathrm{E} 3 \mathrm{E} 4 \mathrm{E} 5 \mathrm{E} 6}\right)$ made justifications based on examples. A statement made by one of these teachers, namely $\mathrm{T}_{\mathrm{E} 6}$ is as follows:

"Let's try a few numbers divisible by 3 . Then let's try a few numbers divisible by 4 . Each number that can be divided into 12 can be divided by... [creates a 
table] ... Let us create a table for 100. Let us include numbers that can be divided both into 3 and 4 in this table... [shows it on the table.] ..." [ $\left.\mathrm{T}_{\mathrm{E} 6}\right]$

These sentences showed that the teacher was justifying his proof based on examples. It can be seen from the task card of $\mathrm{T}_{\mathrm{E} 6}$ that the "Justifications based on examples" skill was performed. Figure 1 is an example for justification based on examples.

Figure 1. An example for Justifications Based one Examples $\left[\mathrm{T}_{\mathrm{E} 6}\right]$

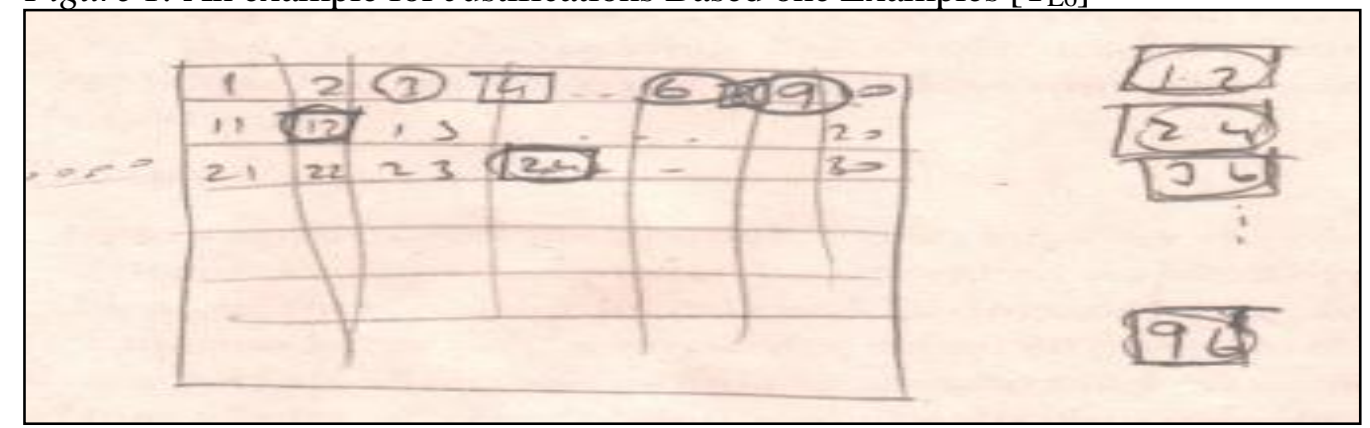

[03.04] R: Is your diagram enough to prove the proposition?

[03.19] $\mathrm{T}_{\mathrm{E} 6}$ : No, not from the point of the proof methods we know. In other words, it does match proof methods like reasoning and deduction. However, I proved it using a model.

[03.56] R: Are the proofs made with diagrams or models valid?

[04.05] $\mathrm{T}_{\mathrm{E} 6}$ : Proofs made with diagrams or models are valid because they give the correct result.

[04.23] R: Then how can we show that a number that can be divided by 7 and 9 can also be divided by 63 ?

[04.47] $\mathrm{T}_{\mathrm{E} 6}$ : We can do it the same way. However, this time a table for 1000 must be formed.

Figure 1 shows that $\mathrm{T}_{\mathrm{E} 6}$ made a proof based on examples. This type of justification requires teachers to use only knowledge. It is not necessary to think about cognition. Thus, the sub-category of "Justifications based on examples" was considered as a cognitive skill. It was observed that five participants $\mathrm{T}_{\mathrm{E} 1 \mathrm{E} 3 \mathrm{E} 4 \mathrm{E} 5 \mathrm{E} 6}$ made pattern generalizations to show the accuracy of the proposition instead of using the inductive method. Below are statements made by $\mathrm{T}_{\mathrm{E} 2}$, which can be given as an example for the generalization pattern.

"I will divide each value I find into 12 . This is 12 once, this is twice, and this is 3 times ... if it goes on like this, then we can reach a result like 12.n. In other words, we can reach the result by generalizing the pattern."

These expressions indicated that $\mathrm{T}_{\mathrm{E} 2}$ made proof via a generalization pattern. This skill is only necessary for cognitive operations and does not require any 
metacognitive awareness. Thus, it was considered that the sub-category of "Generalization pattern" was a cognitive skill.

Two of the elementary math teachers $\left(\mathrm{T}_{\mathrm{E} 2 \mathrm{E} 4}\right)$ used symbolic justification for the proof of the proposition. These teachers used symbolic expression task cards for their proofs and emphasized that their proofs were valid owing to the fact that they were made systematically and by using symbolic expressions. They used metacognitive monitoring and metacognitive awareness to determine the validity of their proofs, thus, the sub-category of "Symbolic justification" was considered as metacognitive skill.

\section{Cognitive and Metacognitive Skills Performed by Secondary Math Teachers in the Proof Process}

The cognitive and metacognitive skills performed by the secondary math teachers in the proof process were collected in three categories: verification, explanation and generalization.

\section{Cognitive and Metacognitive Skills Performed under the Verification Category by the Secondary Math Teachers}

It was determined that the secondary math teachers performed three cognitive and four metacognitive skills relevant to the verification category. The cognitive skills were "Read the proposition in one", "Reading the proposition step by step" and "Basing the proof on a previous theorem". The metacognitive skills were "Reading the proposition repeatedly", "Making a guess", "Drawing a diagram or a table", and "Questioning the correctness of the proposition".

It was observed that $\mathrm{T}_{\mathrm{S} 5}$ read the proposition step by step when she read it for the first time. However, when the other teachers read the proposition for the first time it was seen that they read it as a whole. The reading skills of the secondary math teachers were determined through the observation form. Three of the teachers verified the proposition by basing the proof on a previous theorem. $\mathrm{T}_{\mathrm{S} 6}$ stated that "as there are relatively prime numbers, the proposition is correct. I read in a book that there is such a rule for the number containing relatively prime numbers" and also said "What is this theorem? I tried to remember it... I am thinking whether I proved it or not." These expressions showed that $\mathrm{T}_{\mathrm{S} 6}$ determined the accuracy of the proof through the method he had memorized.

The observation form showed that five secondary math teachers $\left(\mathrm{T}_{\mathrm{S} 1 \mathrm{~S} 4 \mathrm{~S} 5 \mathrm{~S} 6 \mathrm{~S} 8}\right)$ read the proposition repeatedly. The statements of made by the teachers revealed that they re-read the proposition because they didn't understand it. This showed that they were aware of their understanding, in other words they performed metacognitive awareness. Thus, it was considered that the sub-category of "Reading the proposition repeatedly" was a metacognitive skill. Five of secondary math teachers $\left(\mathrm{T}_{\mathrm{S} 155 \mathrm{~S} 6 \mathrm{~S} 7 \mathrm{~S} 8}\right)$ made guesses about the proof of the proposition. For example, $\mathrm{T}_{\mathrm{S} 7}$ said "I think it can be solved from the difference of two squares. Perhaps I will get a result by trying this. But I won't be able to solve it". This expression indicated that $\mathrm{T}_{\mathrm{S} 7}$ was aware of her own knowledge. In other words, 
she had cognitive knowledge. Thus, the "Making a guess" sub-category was considered as a metacognitive skill. $\mathrm{T}_{\mathrm{S} 6}$ drew a diagram for the proof of the proposition and stated that "Proof cannot be done with a model. However, in order to see the proposition more clearly, drawing a diagram and creating a table is important. Of course, it is not one of the proof methods, but makes the event more understandable in our minds."

This statement showed that $\mathrm{T}_{\mathrm{S} 6}$ drew the diagram for comprehension and was aware that drawing a diagram was not proof. This situation requires metacognitive awareness. Thus, the sub-category of "Drawing a diagram or a table" was considered as a metacognitive skill. $\mathrm{T}_{\mathrm{S} 7}$ questioned the correctness of the proposition and stated the following: "I checked if it is correct with a few examples and found that it is. The proposition is correct but I could not reach a general result..." The statement indicated that $\mathrm{T}_{\mathrm{S} 7}$ was questioning the accuracy of the proposition. Questioning is an important part of metacognitive monitoring. Thus, it was considered that the sub-category of "Questioning the correctness of the proposition" was a metacognitive skill.

\section{Cognitive and Metacognitive Skills Performed under the Explanation Category by the Secondary Math Teachers}

It was determined that the secondary math teachers participating in the study performed two cognitive and three metacognitive skills relevant to the explanation category. The cognitive skills were "Trial-error strategy" and "Proving the opposite of the proposition". The metacognitive skills were "Determining a key idea", "Proving it in his/her mind before writing the proof" and "Justified according to the axiomatic proof scheme".

Four secondary math teachers $\left(\mathrm{T}_{\mathrm{S} 2 \mathrm{~S} 4 \mathrm{~S} 5 \mathrm{~S} 8}\right)$ decided whether they could make the proof or not, some teachers made this decision without thinking and preferred to see the proof by trial-error strategy. For example, $\mathrm{T}_{\mathrm{S} 4}$ said that "If nothing in my mind regarding a solution appears, then I try to prove it by trial-error." This expression indicated that $\mathrm{T}_{\mathrm{S} 4}$ used the trial-error strategy. In addition, it also showed that he was not aware of proof. Thus, it was considered that the subcategory of "Trial-error strategy" was a cognitive skill. Two of the secondary math teachers $\left(\mathrm{T}_{\mathrm{S} 3 \mathrm{~S} 8}\right)$ showed that the opposite of the proposition was accurate. When $\mathrm{T}_{\mathrm{S} 3}$, who showed the opposite of the proposition, was asked "Would showing the opposite of the proposition to be correct be adequate in showing the accuracy of the proposition?", he answered by saying "Yes. It is adequate in showing that the proposition is correct." $\mathrm{T}_{\mathrm{S} 8}$, after proving the opposite of the proposition, said: "I do not know if proof can be done by showing the opposite of the proposition, because I had to reach twelve by starting with three and four. Let's try $a=3 k$ and $a=4 l$." These expressions showed that $\mathrm{T}_{\mathrm{S} 8}$ demonstrated cognitive skills in the proving process as she had wrong information and was not aware of this fact.

Six secondary math teachers $\left(\mathrm{T}_{\mathrm{S} 2 \mathrm{~S} 3 \mathrm{~S} 4 \mathrm{~S} 6 \mathrm{~S} 7 \mathrm{~S} 8}\right)$ determined a key idea for proof and outlined the limits of the proof in a general sense. For example, $\mathrm{T}_{\mathrm{S} 4}$ said that "First of all I select the divisor numbers that are divisible into three and four. When I take any a number, it will be the divisible of 3 and 4." These expressions 
showed that $\mathrm{T}_{\mathrm{S} 4}$ determined a key idea, which ensured the detected limit of the proof. In other words, he aimed to make the proof easier. Therefore, as determining a key idea requires an advanced level of skill, it was considered that this sub-category was a metacognitive skill. Four of the secondary math teachers $\left(\mathrm{T}_{\mathrm{S} 1 \mathrm{S4S758}}\right)$ made the proof in their minds before writing it down. For example, $\mathrm{T}_{\mathrm{S} 1}$ said "When I read the question certain things appear in my mind. I check the accuracy in my mind." This showed that $\mathrm{T}_{\mathrm{S} 1}$ solved the proposition in his mind before writing it down. This requires controlled metacognitive. Thus, the subcategory of "Proving it in his/her mind before writing the proof" was considered as a metacognitive skill. Six secondary math teachers $\left(\mathrm{T}_{\mathrm{S} 2 \mathrm{~S} 4 \mathrm{~S} 5 \mathrm{~S} 6 \mathrm{~S} 7 \mathrm{S8})}\right)$ justified their proofs according to the axiomatic proof scheme. Statements from two of the six teachers are given below:

"I believe that the proof I made is correct, because the induction method shows accuracy for all numbers. In other words, if we assume that they resemble dominos, when we trip one domino, they all fall down. Now the operation I have made here is for both 1 and 2. The induction principle is always used for positive integers. Here it verifies for all integers". [ $\left.\mathrm{T}_{\mathrm{S} 2}\right]$

"I am sure that the answer is correct, because I considered all situations by examining them step by step. In other words, I checked all situations. This strengthened my belief that the proof is valid. But I cannot say it is final. I should have checked it, however, I thought that the proof was correct as I had found the result. Nevertheless, I should have checked it." [ $\left.\mathrm{T}_{\mathrm{S} 5}\right]$

These expressions showed that the teachers justified their proofs according to the axiomatic proof scheme. This proof scheme requires a high-order level of thinking and questioning all situations. Thus, the sub-category of "justified according to the axiomatic proof scheme" was considered as a metacognitive skill.

\section{Cognitive and Metacognitive Skills Performed under the Generalization Category by the Secondary Math Teachers}

It was determined that the secondary math teachers performed one cognitive skill and one metacognitive skill relevant to the generalization category. The cognitive skill was "Justifications dependent on authority", while the metacognitive skill was "Symbolic justification".

Four secondary math teachers $\left(\mathrm{T}_{\mathrm{S} 2 \mathrm{~S} 5 \mathrm{~S} 6 \mathrm{~S} 8}\right)$ justified the proof based on authority when they evaluated it. For example, $\mathrm{T}_{\mathrm{S} 8}$ said that "I had seen this proof in a textbook. Therefore, I know that the proof is correct." These expressions indicated $\mathrm{T}_{\mathrm{S} 8}$ evaluated the accuracy of her proof according to a textbook. In other words, it can be said that she evaluated the accuracy of her proof based on authority. Justification that depends on authority doesn't require any metacognitive skill. Thus, it was considered that the sub-category of "Justifications dependent on authority" was a cognitive skill.

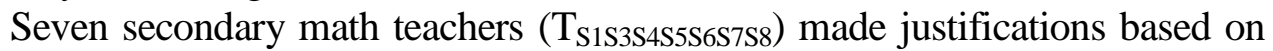
symbolic expressions. Figure 2 and the statements of $\mathrm{T}_{\mathrm{S} 8}$ 's are examples for symbolic justification. 
Figure 2. An Example for Symbolic Justification $\left[\mathrm{T}_{\mathrm{S} 8}\right]$

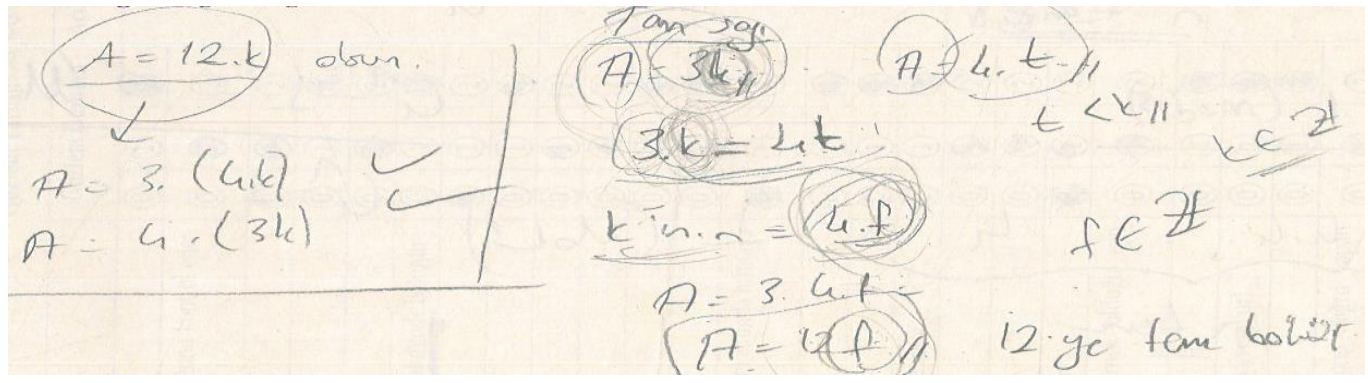

"The proof is not completed but I say it is. Because I know I've forgotten. After all, something clear has to come out; but nothing is clear. We write hypothesis-judgment, we do it all accordingly. This proof is not complete." $\left[\mathrm{T}_{\mathrm{S} 8}\right]$

Figure 2 showed that $\mathrm{T}_{\mathrm{S} 8}$ only used symbolic expressions. Symbolic justification requires the use of unknown and variable concepts, and a high-order level of thinking. Thus, it was considered that the sub-category of "Symbolic justification" was a metacognitive skill.

\section{Comparison of the Cognitive and Metacognitive Skills Performed by Elementary and Secondary Math Teachers in the Proving Process}

Table 2 shows the comparison of cognitive and metacognitive skills performed by elementary and secondary math teachers in the proving process. It can be seen from Table 2 that among the math teachers the most frequently observed sub-category was "Read the proposition in one", and the least frequency observed sub-categories were "Questioning the correctness of the proposition" and "Establishing relationships between the steps". The most frequently observed subcategories among the elementary math teachers were "Read the proposition in one" and "Generalization pattern". Both of these sub-categories were considered as cognitive skills. The most frequently observed sub-categories as metacognitive skills of the elementary math teachers were "Drawing a diagram or a table" and "Proving it in his/her mind before writing the proof". The most frequently observed sub-categories among the elementary math teachers were "Read the proposition in one" and "Symbolic justification". The former of these categories was considered as a cognitive skill, while the latter was a metacognitive skill. The elementary math teachers generally used cognitive skills, while the secondary math teachers generally applied metacognitive skills. 
Table 2.Comparison of the Cognitive and Metacognitive Skills in Performed by the Elementary and Secondary Math Teachers during them Proving Process

\begin{tabular}{|c|c|c|c|c|c|c|c|c|c|c|c|c|c|c|c|c|c|c|c|}
\hline & & & Elen & ntary & ath te & chers & & & & & dary 1 & ath te & hers & & & & & & Total \\
\hline & & Skills & $\mathbf{T}_{\mathrm{E} 1}$ & $\mathbf{T}_{\mathrm{E} 2}$ & $\mathbf{T}_{\mathrm{E3}}$ & $\mathbf{T}_{\mathrm{E} 4}$ & $\mathbf{T}_{\mathrm{E} 5}$ & $\mathbf{T}_{\mathrm{E} 6}$ & f & $\mathbf{T}_{\mathrm{S} 1}$ & $\mathbf{T}_{\mathrm{S} 2}$ & $\mathbf{T}_{\mathrm{S3}}$ & $\mathbf{T}_{\mathrm{S} 4}$ & $\mathbf{T}_{\mathrm{S} 5}$ & $\mathbf{T}_{\mathbf{S 6}}$ & $\mathbf{T}_{\mathrm{S} 7}$ & $\mathbf{T}_{\mathrm{S} 8}$ & f & tf \\
\hline \multirow{9}{*}{ 莺 } & \multirow[t]{4}{*}{ Verification } & Read the proposition in one & $\mathrm{X}$ & & $\mathrm{X}$ & $\mathrm{X}$ & $\mathrm{X}$ & $\mathrm{X}$ & 5 & $\mathrm{X}$ & $\mathrm{X}$ & $\mathrm{X}$ & $\mathrm{X}$ & & $\mathrm{X}$ & $\mathrm{X}$ & $\mathrm{X}$ & 7 & 12 \\
\hline & & Reading the proposition step by step & & $\mathrm{X}$ & & & & & 1 & & & & & $\mathrm{X}$ & & & & 1 & 2 \\
\hline & & $\begin{array}{l}\text { Heuristically checking the } \\
\text { proposition }\end{array}$ & $X$ & $\mathrm{X}$ & & & & & 2 & & & & & & & & & - & 2 \\
\hline & & $\begin{array}{l}\text { Basing the proof on a previous } \\
\text { theorem }\end{array}$ & & & & & & & - & & $\mathrm{X}$ & & & $\mathrm{X}$ & $X$ & & & 3 & 3 \\
\hline & \multirow[t]{2}{*}{ Explanation } & Trial-error strategy & & & & & $\mathrm{X}$ & $\mathrm{X}$ & 2 & & $\mathrm{X}$ & & $\mathrm{X}$ & $\mathrm{X}$ & & & $\mathrm{X}$ & 4 & 6 \\
\hline & & $\begin{array}{l}\text { Proving the opposite of the } \\
\text { proposition }\end{array}$ & & $\mathrm{X}$ & & & & & 1 & & & $X$ & & & & & $\mathrm{X}$ & 2 & 3 \\
\hline & \multirow[t]{3}{*}{ Generalization } & Justification dependent on authority & & $\mathrm{X}$ & & & & & 1 & & $\mathrm{X}$ & & & $\mathrm{X}$ & $\mathrm{X}$ & & $\mathrm{X}$ & 4 & 5 \\
\hline & & Justification dependent on examples & & & $\mathrm{X}$ & $\mathrm{X}$ & $\mathrm{X}$ & $\mathrm{X}$ & 4 & & & & & & & & & - & 4 \\
\hline & & Pattern generalization & & $\mathrm{X}$ & $\mathrm{X}$ & $\mathrm{X}$ & $\mathrm{X}$ & $\mathrm{X}$ & 5 & & & & & & & & & - & 5 \\
\hline \multirow{11}{*}{ 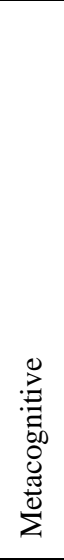 } & \multirow[t]{4}{*}{ Verification } & Reading the proposition repeatedly & $\mathrm{X}$ & $\mathrm{X}$ & & & & & 2 & $\mathrm{X}$ & & & $\mathrm{X}$ & $\mathrm{X}$ & $\mathrm{X}$ & & $\mathrm{X}$ & 5 & 7 \\
\hline & & Making a guess & & $\mathrm{X}$ & & & & & 1 & $\mathrm{X}$ & & & & $\mathrm{X}$ & $\mathrm{X}$ & $\mathrm{X}$ & $\mathrm{X}$ & 5 & 6 \\
\hline & & Drawing a diagram or a table & & & $\mathrm{X}$ & $\mathrm{X}$ & $\mathrm{X}$ & $\mathrm{X}$ & 4 & & & & & & $\mathrm{X}$ & & & 1 & 5 \\
\hline & & $\begin{array}{l}\text { Questioning the correctness of the } \\
\text { proposition }\end{array}$ & & & & & & & - & & & & & & & $\mathrm{X}$ & & 1 & 1 \\
\hline & \multirow[t]{6}{*}{ Explanation } & Determining a key idea & $\mathrm{X}$ & & & & & & 1 & & $\mathrm{X}$ & $\mathrm{X}$ & $\mathrm{X}$ & & $\mathrm{X}$ & $\mathrm{X}$ & $\mathrm{X}$ & 6 & 7 \\
\hline & & $\begin{array}{l}\text { Proving it in his/her mind before } \\
\text { writing the proofproof }\end{array}$ & & $\mathrm{X}$ & $X$ & & $\mathrm{X}$ & $X$ & 4 & $\mathrm{X}$ & & & $\mathrm{X}$ & & & $\mathrm{X}$ & $X$ & 4 & 8 \\
\hline & & Making a decision & $\mathrm{X}$ & $\mathrm{X}$ & & & & & 2 & & & & & & & & & - & 2 \\
\hline & & Questioning the proving process & $\mathrm{X}$ & $\mathrm{X}$ & $\mathrm{X}$ & & & & 3 & & & & & & & & & - & 3 \\
\hline & & $\begin{array}{l}\text { Establishing relationship between } \\
\text { the steps }\end{array}$ & $\mathrm{X}$ & & & & & & 1 & & & & & & & & & - & 1 \\
\hline & & $\begin{array}{l}\text { Justified according to the axiomatic } \\
\text { proof scheme }\end{array}$ & & & & & & & - & & $\mathrm{X}$ & & $X$ & $X$ & $X$ & $\mathrm{X}$ & $X$ & 6 & 6 \\
\hline & Generalization & Symbolic justification & & $\mathrm{X}$ & & $\mathrm{X}$ & & & 2 & $\mathrm{X}$ & & $\mathrm{X}$ & $\mathrm{X}$ & $\mathrm{X}$ & $\mathrm{X}$ & $\mathrm{X}$ & $\mathrm{X}$ & 7 & 9 \\
\hline
\end{tabular}




\section{Conclusion and Discussion}

The present study aimed to determine and compare the cognitive and metacognitive skills performed by elementary and secondary math teachers during the proving process. The cognitive skills performed by math teachers regarding reading the proposition were "Read the proposition in one" and "Reading the proposition step by step". Öztürk and Kaplan (2019) reported that skills related to reading were cognitive skill. Yang (2012) expressed that reading step by step for the proving process was a cognitive skill. The relevant result obtained in the present study was consistent with the results of these studies. It was observed that elementary math teachers heuristically checked the accuracy of the proposition. This result confirms the earlier findings of Öztürk and Kaplan (2019). The secondary math teachers, on the other hand, checked the accuracy of the proposition based on previous theorems. This finding was also consistent with the findings of the earlier studies of Öztürk and Kaplan (2019). Many teachers decided whether they could make the proof or not, some teachers made this decision without thinking and preferred to see by trying to make the proof. In this sense, the trial-error strategy for the proving process was considered as a cognitive skill. This finding was consistent with the findings of earlier studies on proof and problemsolving (Cozza \& Oreshkina, 2013; Öztürk \& Kaplan, 2019). Many of the teachers chose to prove the opposite of the proposition. This result was in line with the findings obtained by Stavrou (2014). It was determined that the elementary and secondary math teachers justified the proof of the proposition based on authority. This finding was consistent with the findings of previous studies (Harel \& Sowder, 1998; Öztürk \& Kaplan, 2019). Elementary math teachers were found to justify their proof based on examples. This result confirms earlier findings (Harel \& Sowder, 1998). Many elementary math teachers chose pattern generalization for their proof. There are studies in this field that have declared that pattern generalization is a cognitive skill (Čadež \& Kolar, 2015; Öztürk \& Kaplan, 2019).

It was determined that reading the proposition repeatedly was a metacognitive skill, as it requires to be aware of why one reads the proposition repeatedly. Yang (2012) reported that reading a proposition repeatedly was a metacognitive skill. The relevant result of the present study was consistent with the results of their study. Some of the math teachers in the present study made guesses to make their proof. Making a guess was considered as a metacognitive skill, as it requires metacognitive control. Schraw (1998) pointed out that "making a guess by determining a target" was a metacognitive skill aimed at planning. Everson and Tobias (1998) also emphasized that guessing was a metacognitive skill. This finding is consistent with the findings of previous studies. The results also revealed both elementary and secondary math teachers drew diagrams or tables during the proof process. When the relevant results were compared, it was found that diagrams and tables were used to comprehend the proposition. However, this method was not really preferred by secondary math teachers. Gourgey (1998) stated that drawing a shape is important for understanding, and that this skill is metacognitive. Depaepe, Corte and Verschaffel (2010) also expressed that drawing shapes or making a table during problem solving processes are metacognitive 
skills. However, contrary of these statements, Yang (2012) determined that drawing a shape during a proof process to understand what is being said was a cognitive skill. Yang's (2012) study is a scale development work, and the fact that no interviews were made, may have caused him to assess this skill as a cognitive skill. Secondary math teachers questioned the correctness of the proposition. This skill was considered as a metacognitive skill, because questioning is a part of metacognitive monitoring. Many studies have reported that questioning is a metacognitive skill (Öztürk \& Kaplan, 2019; Öztürk et al., 2019).

The math teachers also determined a key idea for proof. The relevant statements of the math teachers showed that they were aware of the importance of determining a key idea. This finding was consistent with the findings of previously conducted studies (Öztürk \& Kaplan, 2019; Raman, 2003). The results of the present study showed that the math teachers made the proof in their minds before writing it down. They stated that they did so to check it first. Thus, this subcategory was considered as a metacognitive skill. Öztürk and Kaplan (2009) emphasized that secondary math teachers made the proofs in their minds first and then actualized them. This result of the present study was consistent with their study. Many elementary math teachers made a decision with proof. Their expressions showed that they had knowledge of cognition. Thus, it was considered that the sub-category of "Making a decision" was a metacognitive skill. Öztürk and Kaplan (2019) reported that making a decision was a metacognitive skill. This result is consistent with prior research. Many elementary math teachers established relationships between the steps of the proof. It was considered that this skill was a metacognitive skill, because establishing relationships is necessary for metacognitive monitoring. This finding is consistent with the findings of earlier studies (Schoenfeld, 1985; Yang, 2012). Secondary math teachers justified their proof according to the axiomatic proof scheme. The axiomatic proof scheme requires a high-order level of thinking and questioning all situations (Tall \& Mejia-Ramos, 2010). The math teachers also justified their proof using symbolic expressions. Schoenfeld (1985) stated that the use of symbolic expressions was a metacognitive skill. In contrast, Yang (2012) indicated that the use of symbolic expressions for reading proofs was a cognitive skill.

This study was conducted with several limitations. The number of participants was the first of these limitations. As the study was conducted according to the case study model, a qualitative research design, it was aimed to make a detailed investigation and therefore the sample was limited. Future researchers could conduct studies examining the proof process by using mixed research methods with larger samples. Another limitation of the study was that only the cognitive structure was considered. Recently, considering the developments in medical science, it is also possible to examine mental structures with the help of Functional Magnetic Resonance Imaging (FMRI) and Positron-Emission Tomography (PET). In this context, future researchers can examine the mental process of making proofs.

The results of this study showed that elementary math teachers generally used cognitive skills, while secondary math teachers generally applied metacognitive skills. Given that proof is important for school mathematics, teachers are expected 
to make better proofs and know what they are doing and why. In other words, the high number of metacognitive skills used by teachers is important for students to learn mathematics meaningfully. In this context, the use of metacognition-based instructions in the courses for proof-making skills may contribute to the development of metacognitive skills performed by teachers in the process of making proofs.

\section{References}

Akın, A. (2013). Bilişötesi. In Güncel psikolojik kavramlar 1: Pozitif psikoloji A. Akın (ed.), (pp. 114-164). Sakarya: Sakarya Üniversitesi Eğitim Bilimleri Enstitüsü.

Aydoğdu-İskenderoğlu, T. (2016). Kanıt ve kanıt şemaları. In Matematik eğitiminde teoriler, E. Bingölbali, S. Arslan, \& İ. Ö. Zembat (eds.), (pp. 65-84). Ankara: Pegem Akademi.

Baxter, P., \& Jack, S. (2008). Qualitative case study methodology: Study design and implementation for novice researchers. The Qualitative Report, 13(4), 544-559.

Čadež, T.H., \& Kolar, V.M. (2015). Comparison of types of generalizations and problemsolving schemas used to solve a mathematical problem. Educational Studies in Mathematics, 89(2), 283-306. https://doi.org/10.1007/s10649-015-9598-y.

Cozza, B., \& Oreshkina, M. (2013). Cross-cultural study of cognitive and metacognitive processes during math problem solving. School Science and Mathematics, 113(6), 275-284. https://doi.org/10.1111/ssm.12027

Creswell, J.W. (2007). Qualitative inquiry and research design: choosing among five approaches (Second edition). Thousand Oaks, London, New Delhi: Sage Publication.

Dawkins, P.C., \& Weber, K. (2017). Values and norms of proof for mathematicians and students. Educational Studies in Mathematics, 95(2), 123-142. https://doi.org/10.10 07/s10649-016-9740-5.

Depaepe, F., Corte, E.D. \& Verschaffel, L. (2010). Teachers' metacognitive and heuristic approaches to word problem solving: analysis and impact on students' beliefs and performance. ZDM Mathematics Education, 42(2), 205-218. https://doi.org/10.1007/ s11858-009-0221-5.

Everson, H.T. \& Tobias, S. (1998). The ability to estimate knowledge and performance in college: A metacognitive analysis. Instructional Science, 26(1), 65-79. https://doi.org/ 10.1023/A:1003040130125.

Flavell, J.H. (1976). Metacognitive aspects of problem solving. In The Nature of Intelligence, L. B. Resnick (ed.), (pp. 231-236). Hillsdale, NJ: Erlbaum.

Forrest-Pressley, D.L., \& Waller, T.G. (1984). Reading, cognition and metacognition. New York: Springer-Verlag.

Garner, R., \& Alexander, P.A. (1989). Metacognition: Answered and unanswered questions. Educational Psychologist, 24(2), 143-158. https://doi.org/10.1207/s15326 985ep2402_2.

Gourgey, A. F. (1998). Metacognition in basic skills instruction. Instructional Science, 26(1-2), 81-96. https://doi.org/10.1023/A:1003092414893.

Hanna, G., \& de Villiers, M. (2008). ICMI Study 19: Proof and proving in mathematics education. ZDM Mathematics Education, 40(2), 329-336. https://doi.org/10.1007/s1 1858-008-0073-4.

Harel, G., \& Sowder, L. (1998). Students' proof schemes: Results from exploratory studies. In Research in collegiate mathematics education III (Cbms issues in mathematics 
education), J. Kaput, A. H. Schoenfeld \& E. Dubinsky (eds.), (pp. 234-283). Washington, DC: American Mathematical Society.

Husamah, H. (2015). Blended Project based learning: Metacognitive awareness of biology education new students. Journal of Education and Learning, 9(4), 274-281.

Knuth, E.J. (2002). Teachers' conceptions of proof in the context of secondary school mathematics. Journal of Mathematics Teacher Education, 5(1), 61-88. https://doi. org/10.1023/A:1013838713648.

Landis, J.R., \& Koch, G.G. (1977). The measurement of observer agreement for categorical data. Biometrics, 33, 159-174. https://doi.org/10.2307/2529310.

Öztürk, M., \& Kaplan, A. (2019). Cognitive analysis of constructing algebraic proof processes: A mixed method research. Education and Science, 44(197), 25-64. https://doi.org/10.15390/EB.2018.7504.

Öztürk, M., Akkan, Y., \& Kaplan, A. (2019). Cognitive structures and arguments of elementary school student teachers' during process of basic mathematics proofs. Cumhuriyet International Journal of Education, 8(2), 429-452. http://dx.doi.org/10. 30703/cije.490887.

Raman, M. (2003). Key Ideas: What are they and how can they help us understand how people view proof? Educational Studies in Mathematics, 52(3), 319-325. https://doi. org/10.1023/A:1024360204239.

Schoenfeld, A.H. (1985). Mathematical problem-solving. Orlando, FL: Academic Press.

Schraw, G. (1998). Promoting general metacognitive awareness. Instructional Science, 26(1-2), 113-125. https://doi.org/10.1023/A:1003044231033.

Spruce, R., \& Bol, L. (2015). Teacher beliefs, knowledge, and practice of self-regulated learning. Metacognition and Learning, 10(2), 245-277. https://doi.org/10.1007/s1140 9-014-9124-0

Stavrou, S.G. (2014). Common errors and misconceptions in mathematical proving by education undergraduates. Issues in the Undergraduate Mathematics Preparation of School Teachers, 1(1), 1-8.

Tall, D., \& Mejia-Ramos, J. P. (2010). The long-term cognitive development of reasoning and proof. In Explanation and proof in mathematics: Philosophical and educational perspectives, G. Hanna, H. Niels, \& J. H. Pulte (eds.), (pp. 137-150). New York, NY: Springer. https://doi.org/10.1007/978-1-4419-0576-5_10.

Veenman, M.V., Hout-Wolters, B.H., \& Afflerbach, P. (2006). Metacognition and learning: conceptual and methodological considerations. Metacognition and Learning, 1(1), 3-14. https://doi.org/10.1007/s11 409-006-6893-0.

Weinert, F. (1987). Metacognition and motivation as determinants of effective learning and understanding. In F. Weinert \& R. Kluwe (Eds.), Metacognition, motivation, and understanding (pp. 1-15). Hillsdale, NJ: Erlbaum.

Winne, P.H., \& Azevedo, R. (2014). Metacognition. In R. K. Sawyer (Ed.) The Cambridge Handbook of the Learning Sciences, (pp. 63-87). New York: Cambridge University Press.

Yang, K.-L. (2012). Structures of cognitive and metacognitive reading strategy use for reading comprehension of geometry proof. Educational Studies in Mathematics, 80(3), 307-326. https://doi. org/10.1007/s10649-011-9350-1. 
